University of Nebraska - Lincoln

DigitalCommons@University of Nebraska - Lincoln

Faculty Papers and Publications in Animal

Science

Animal Science Department

October 2005

\title{
Incidence of splayleg pigs in Nebraska litter size selection lines
}

J. W. Holl

University of Nebraska-Lincoln

R. K. Johnson

University of Nebraska-Lincoln, rjohnson5@unl.edu

Follow this and additional works at: https://digitalcommons.unl.edu/animalscifacpub

Part of the Animal Sciences Commons

Holl, J. W. and Johnson, R. K., "Incidence of splayleg pigs in Nebraska litter size selection lines" (2005).

Faculty Papers and Publications in Animal Science. 70.

https://digitalcommons.unl.edu/animalscifacpub/70

This Article is brought to you for free and open access by the Animal Science Department at DigitalCommons@University of Nebraska - Lincoln. It has been accepted for inclusion in Faculty Papers and Publications in Animal Science by an authorized administrator of DigitalCommons@University of Nebraska - Lincoln. 


\title{
Incidence of splayleg pigs in Nebraska litter size selection lines ${ }^{1}$
}

\author{
J. W. Holl and R. K. Johnson ${ }^{2}$ \\ Department of Animal Science, University of Nebraska, Lincoln 68581-0908
}

\begin{abstract}
Genetic parameters for the splayleg (SL) condition were estimated from 37,673 records of pigs from six lines derived from a Large White-Landrace base population. Random selection for 22 generations was practiced in Lines $\mathrm{C} 1$ and $\mathrm{C} 2$. Line $\mathrm{C} 2$ was derived from $\mathrm{C} 1$ at Generation 8. Selection lines were as follows: 1) Line I, selected 11 generations for an index of ovulation rate and embryonic survival followed by 11 generations of selection for litter size; 2) Line IOL, derived from Line I at Generation 8 and which underwent eight generations of two-stage selection for ovulation rate and number of fully formed pigs per litter followed by four generations of litter size selection; 3) Line COL, derived from Line $\mathrm{C} 1$ at Generation 8 and selected eight generations in two stages for ovulation rate and number of fully formed pigs followed by four generations of litter size selection; and 4) Line T, selected 12 generations for increased testis size. From logistic models, it was found that boars were $224 \%$ more likely to have SL than gilts $(P<0.01)$. Decreases in birth weight, dam age at puberty, dam nipple number, and dam embryonic survival, and increases in dam lit-
\end{abstract}

ter size and inbreeding increased the odds of SL $(P<$ 0.05). Direct and maternal heritabilities of SL were 0.07 and 0.16 , respectively, and the correlation between direct and maternal effects was -0.24 . Correlations between direct genetic effects for SL and number born alive, nipple number, birth weight, age at puberty, and embryonic survival were $-0.19,-0.36,0.23,-0.19$, and -0.32 , respectively. Except for the correlation of 0.32 between maternal effects for SL and direct effects for number of live pigs, correlations of SL maternal genetic effects with direct genetic effects of other traits were less than 0.11. Annual direct genetic trends (\%) for SL in I, IOL, COL, T, C1, and C2 were $-0.003 \pm 0.003$, $0.121 \pm 0.012,-0.273 \pm 0.009,0.243 \pm 0.014,-0.274 \pm$ 0.004 , and $0.086 \pm 0.008$, respectively; annual maternal genetic trends $(\%)$ were $0.106 \pm 0.004,0.508 \pm 0.019$, $0.383 \pm 0.015,0.527 \pm 0.024,0.188 \pm 0.005$, and 0.113 \pm 0.012 , respectively. Annual genetic maternal trend in Line I after Generation 12 was $0.339 \pm 0.014$. Maternal breeding value for SL is expected to increase as a correlated response to selection for increased litter size and increased size of testes.

Key Words: Genetic Parameters, Pigs, Selection, Splayleg

(C2005 American Society of Animal Science. All rights reserved.

J. Anim. Sci. 2005. 83:34-40

\section{Introduction}

Although increasing litter size is economically important, preweaning mortality constitutes a major loss to the swine industry (Jirmanova, 1983; Tess et al., 1983; Partlow et al., 1993). Splayleg (SL) is the most common birth defect, and survival of pigs with splaylegs is 50\% (Vogt et al., 1984). Results from Dobson (1968), Vogt et al. (1984), and Tomko (1993) indicate that the incidence of SL is greater in Landrace than in other breeds. Lax (1971) suggested that SL incidence was sexlinked with varying degrees of penetrance. However,

\footnotetext{
${ }^{1}$ Published as Paper No. 14603 Journal Ser., Nebraska Agric. Res. Div., Univ. of Nebraska, Lincoln 68583-0908.

${ }^{2}$ Correspondence-phone: 402-472-6404; fax: 402-472-6362; email: rjohnson5@unl.edu.

Received May 20, 2004.

Accepted September 28, 2004.
}

Dobson (1968) and Vogt et al. (1984) suggested that SL incidence was polygenic, and Sellier and Olivier (1982) determined that maternal effects were also important. Further, Svendson et al. (1991) found that the incidence of SL pigs increased with increased litter size.

Four selection lines, three for litter size and its component traits, and one for testis size, were created from a Large White-Landrace composite population with the objective of improving litter size. Selection for litter size and its components was effective (Johnson et al., 1999; Ruiz-Flores and Johnson, 2001). Testis size increased approximately $50 \%$ in 10 generations of selection, but correlated response in litter size was not significant (Johnson et al., 1994).

Splayleg incidence and data on other traits were collected on pigs in these selection lines and their randomly selected controls and analyzed with the objectives of 1) identifying variables affecting the incidence of SL, 2) estimating genetic parameters for SL, and 3) 
estimating correlated responses in incidence of SL to litter size and testis size selection.

\section{Materials and Methods}

\section{Population}

The population was a composite of Large White and Landrace formed in 1979. After two generations of random mating, a line selected for increased index of ovulation rate and embyonic survival (Line I), a control line (C1), and a testis size selection line (Line T) were created and selection began as described by Johnson et al. (1994, 1999). Twelve generations of selection were practiced in Line $\mathrm{T}$, and then the line was terminated. Details of this selection and responses are reported by Johnson et al. (1994).

Index selection in Line I was terminated after 11 generations, and selection for increased number of fully formed (FF) pigs per litter was practiced from Generations 12 through 14. Selection criteria and responses through 14 generations are given by Johnson et al. (1999). During Generations 15 to 19, between-litter selection for number of live pigs born and within-litter selection for increased birth weight was practiced in Line I, and selection during Generations 20 to 22 was for increased number of live pigs born and within-litter selection for increased growth rate, decreased backfat, and increased LM area. Lines I, T, and C1 were contemporary. Details of selection and responses in Lines I and $\mathrm{C} 1$ through Generation 19 are provided in Petry and Johnson (2004).

Selected, Generation 8 parents in Lines C1 and I were remated within line after females produced their first litter to create a control line and two lines in which two-stage selection for ovulation rate and number of fully formed pigs was practiced. Pigs in Line C1 secondparity litters were randomly assigned within litter to a control line (Line C2) or to a two-stage selection line (Line COL). The Line I litters were the base for the other two-stage selection line (Line IOL). Lines IOL, $\mathrm{COL}$, and $\mathrm{C} 2$ were contemporary and farrowed at a 6 mo interval to lines I and C1. Selection criteria and responses in Lines IOL, COL, and C2 after eight generations of two-stage selection (corresponding with 16 total generations) are given in Ruiz-Flores and Johnson (2001). Generations in Lines IOL, COL, and C2 will be referenced from the initiation of selection in the base composite population. Selection in Lines IOL and COL during Generation 17 was for litter size and birth weight, and subsequent selection was for litter size, growth, backfat, and LM area as described previously for Line I.

The number of boars that sired litters per line each generation ranged from 14 to 20 , and the number of litters ranged from 36 to 90 . Inbreeding was estimated to increase at a rate of $0.78,1.21,1.29,0.84$, and $0.75 \%$ per year in Lines C1, I, IOL, COL, and C2, respectively (Johnson et al., 1999; Ruiz-Flores and Johnson, 2001).

\section{Data}

Within 24 h of birth, sex, birth weight (BWT), number of nipples $(\mathbf{N N})$, and birth abnormalities were recorded. Age at puberty $(\mathbf{A P})$ was recorded in gilts of Lines I and $\mathrm{C} 1$ from Generations 2 through 15, in Line $\mathrm{T}$ through Generation 12, and in gilts of Lines IOL, COL, and C2 through Generation 16. Ovulation rate was recorded in gilts of Lines I and C1 through Generation 11, and in gilts of Lines IOL, COL, and C2 through Generation 16. Embryonic survival (ES) was recorded in gilts of Lines I and C1 from Generations 1 to 11 . Age at farrowing, number FF, number of mummified pigs, number of stillborn pigs, and number of pigs born alive (BA) were recorded in all litters. The inbreeding coefficient of each pig was calculated.

A total of 37,673 records on BA were used. Table 1 shows the number of BA and SL pigs, the number of gilts with AP, ovulation rate, and ES records by line and generation since the initiation of selection in the composite population in 1981. Splayleg pigs were not recorded in Generation 0 or 9 in Lines IOL, COL, and $\mathrm{C} 2$.

\section{Statistical Procedures}

Birth weight and the SL condition were considered to be traits of the pig, and all other traits were considered to be traits of the dam (i.e., dam age at puberty, dam age at farrowing, etc.). Splayleg incidence was analyzed with a generalized linear model assuming a binomial distribution with the GENMOD procedures of SAS (SAS Inst., Inc., Cary, NC) to determine variables associated with SL. Linear predictors of SL incidence were computed in the following logistic regression model: $\operatorname{logit}(\pi)=\mathrm{X} \beta$, where $\pi$ is the vector of predicted probabilities, $\mathrm{X}$ is the coefficient matrix, and $\beta$ is the solution vector. Probabilities were calculated by applying the inverse link function $\pi=\exp (\mathrm{X} \beta) /[1+\exp (\mathrm{X} \beta)]$. Odds ratios were calculated for effects in the model that were significant $(P<0.10)$.

Linear mixed models were used to estimate genetic parameters and genetic trends. This procedure has the limitation that effects in the model are estimated assuming normality and, therefore, extrapolation could lead to negative incidence rates; however, with a large sample size, this approximation method is fairly robust. The logistic model fits binary data better and will keep extrapolated incidence rates from becoming negative (Collett, 2002). Nonetheless, multiple-trait analyses are computationally difficult with a mixture of binary traits and normal traits. Consequently, linear mixed models were used to estimate genetic parameters.

Genetic parameters were estimated with an animal model using the MTDFREML programs described by Boldman et al. (1995). Depending on the trait, models (see Table 2) were derived from the following linear animal model:

$$
y=X \beta+Z_{d} a_{d}+Z_{m} a_{m}+e
$$


Table 1. Number of observations for pigs born alive (BA), splayleg pigs (SL), age at puberty (AP), ovulation rate (OR), and embryonic survival (ES) by contemporary group (CG) and generation

\begin{tabular}{|c|c|c|c|c|c|c|c|c|c|}
\hline \multirow[b]{2}{*}{ Generation $^{\mathrm{b}}$} & \multicolumn{4}{|c|}{$\mathrm{CG} 1^{\mathrm{a}}$} & \multicolumn{5}{|c|}{$\mathrm{CG} 2^{\mathrm{a}}$} \\
\hline & BA & SL & $\mathrm{AP}$ & OR & ES & BA & SL & $\mathrm{AP}$ & OR \\
\hline 1 & 1,409 & 50 & - & 150 & 150 & - & - & - & - \\
\hline 2 & 1,171 & 53 & 255 & 157 & 155 & - & - & - & - \\
\hline 3 & 1,202 & 46 & 278 & 171 & 171 & - & - & - & - \\
\hline 4 & 1,175 & 62 & 282 & 171 & 171 & - & - & - & - \\
\hline 5 & 1,189 & 29 & 326 & 186 & 165 & - & - & - & - \\
\hline 6 & 1,173 & 26 & 288 & 151 & 151 & - & - & - & - \\
\hline 7 & 1,233 & 83 & 290 & 186 & 186 & - & - & - & - \\
\hline 8 & 1,200 & 51 & 286 & 194 & 194 & - & - & - & - \\
\hline $9(1)$ & 1,152 & 53 & 267 & 177 & 177 & - & - & - & - \\
\hline $10(2)$ & 1,154 & 84 & 377 & 175 & 175 & 1,164 & 49 & 244 & 193 \\
\hline $11(3)^{c}$ & 1,299 & 80 & 160 & 210 & 210 & 1,407 & 53 & - & - \\
\hline $12(4)$ & 1,306 & 58 & 145 & - & - & 1,179 & 41 & 258 & 180 \\
\hline $13(5)$ & 921 & 40 & 160 & - & - & 1,195 & 79 & 232 & 210 \\
\hline $14(6)$ & 1,218 & 22 & 159 & - & - & 1,179 & 47 & 241 & 236 \\
\hline $15(7)$ & 1,503 & 49 & 172 & - & - & 1,224 & 55 & 236 & 225 \\
\hline $16(8)$ & 1,350 & 43 & - & - & - & 1,295 & 94 & 247 & 240 \\
\hline $17(9)$ & 777 & 20 & - & - & - & 1,085 & 50 & - & - \\
\hline $18(10)$ & 706 & 16 & - & - & - & 1,393 & 83 & - & - \\
\hline 19 (11) & 696 & 25 & - & - & - & 1,408 & 70 & - & - \\
\hline $20(12)^{\mathrm{d}}$ & 1,075 & 13 & - & - & - & 298 & 3 & - & - \\
\hline $21(13)^{\mathrm{d}}$ & 835 & 17 & - & - & - & 351 & 9 & - & - \\
\hline 22 & 751 & 10 & - & - & - & - & - & - & - \\
\hline Total & 24,495 & 930 & 3,445 & 1,928 & 1,905 & 13,178 & 633 & 1,622 & 1,407 \\
\hline
\end{tabular}

${ }^{\mathrm{a}} \mathrm{CG} 1$ = Lines C1, I, and T; CG2 = Lines IOL, COL, and C2.

${ }^{\mathrm{b}}$ Generations from initiation of selection in composite founder population. Numbers in parentheses indicate generations of selection practiced in CG2 since diverging from CG1.

${ }^{\mathrm{c}} \mathrm{Age}$ at puberty and ovulation rate were not measured in Generation 3 gilts in CG2.

${ }^{\mathrm{d}}$ Number of observations in CG2 are from Line C2.

where $y$ represents the vector of observations, $X, Z_{d}$, and $Z_{m}$ are known design matrices, $\beta$ represents the vector of fixed effects, $a_{d}$ is the vector of random additive direct genetic effects, $a_{m}$ is the vector of random additive maternal genetic effects, and $e$ is the vector of random residual effects. Expectations and variances of random variables are as follows:

$$
\begin{gathered}
\mathrm{E}\left[\begin{array}{c}
a_{d} \\
a_{m} \\
e
\end{array}\right]=\left[\begin{array}{l}
0 \\
0 \\
0
\end{array}\right] \\
\mathrm{V}\left[\begin{array}{c}
a_{d} \\
a_{m} \\
e
\end{array}\right]=\left[\begin{array}{ccc}
G_{d} \otimes A & G_{d m} \otimes A & 0 \\
G_{d m} \otimes A & G_{m} \otimes A & 0 \\
0 & 0 & R_{0} \otimes I
\end{array}\right]
\end{gathered}
$$

where $\otimes$ denotes a direct product operation; $G_{d}, G_{d m}$, $G_{m}$, and $R_{0}$ are additive genetic, additive $\times$ maternal genetic, maternal genetic, and residual covariance matrices, respectively, with order equal to the number of traits in the analysis; $A$ is the numerator relationship matrix; and $I$ is an identity matrix of appropriate order.

Splayleg incidence and BA per litter were analyzed together. When a common litter environmental component for SL was included, convergence could not be obtained; thus, the common litter variance was assumed to be zero. After fitting SL and BA in a two-trait model, three-trait analyses including these traits and one other trait were performed. Only traits found to significantly affect SL in logistic models were included. Variance components, heritabilities, genetic correlations, and EBV were obtained from three-trait analyses. Estimated breeding values were regressed on generation to estimate direct and maternal genetic trends within lines. Because selection in all lines except Line $\mathrm{T}$ was either random or for increased number of live pigs born, unbiased estimates of variance components and responses are expected (Sorensen and Johansson, 1992).

\section{Results}

The incidence of SL in Lines I, C1, and T across generations is shown in Figure 1. The incidence was consistently greatest in Line T. Until Generation 9, the incidence was less in Line I than in Line C1, but after Generation 10, the incidence in Line I relative to Line $\mathrm{C} 1$ tended to increase.

The incidence of SL in Lines IOL, COL, and C2 is shown in Figure 2. After Generation 10, percentage of pigs born SL in Line IOL exceeded Line C2 by 2.6 units. 
Table 2. Models used to estimate genetic parameters

\begin{tabular}{lll}
\hline \hline Trait $^{\mathrm{a}}$ & Fixed effects & Random effects \\
\hline SL & Generation, Sex & Animal, Maternal \\
BA & Generation & Animal \\
NN & Generation & Animal \\
BWT & Generation, Sex & Animal, Maternal \\
AP & Generation & Animal \\
ES & Generation & Animal \\
\hline
\end{tabular}

${ }^{\text {a SL }}=$ splayleg; BWT = individual birth weight; BA = number of pigs born alive; $\mathrm{NN}=$ number of nipples; $\mathrm{AP}=$ age at puberty; and $\mathrm{ES}=$ embryonic survival at $50 \mathrm{~d}$.

The incidence of SL pigs tended to be greater in Line COL than in Line C2 after Generation 10.

Means, minimums, maximums, and within-line and generation variances for traits tested for association with SL condition are shown in Table 3. Significant variables associated with SL condition were sex, line, generation, line $\times$ generation interaction, birth weight, dam BA, dam NN, dam AP, dam ES, and inbreeding of the dam.

Percentage increases in the likelihood of the SL condition from deviations from the population mean for traits significantly associated with SL in logistic regression models are shown in Table 4. The likelihood of SL was $223.6 \%$ greater in males than females. Regression coefficients on continuous variables in the model are expressed as the percent increase in the likelihood of SL per change in the trait as a deviation from the population mean. For example, the logistic regression of incidence of SL per decrease of $10 \mathrm{~g}$ in BWT was 0.015 , interpreted as an increase of $1.5 \%$ in the likelihood of SL for a deviation of $-10 \mathrm{~g}$ from the population mean BWT. Additional deviations from the population mean produce exponential rather than linear increases in the likelihood so that a decrease of $20 \mathrm{~g}$ in BWT increased the likelihood of SL by $100 \times\left[(1+1.5 / 100)^{2}-1\right]=3.02 \%$,

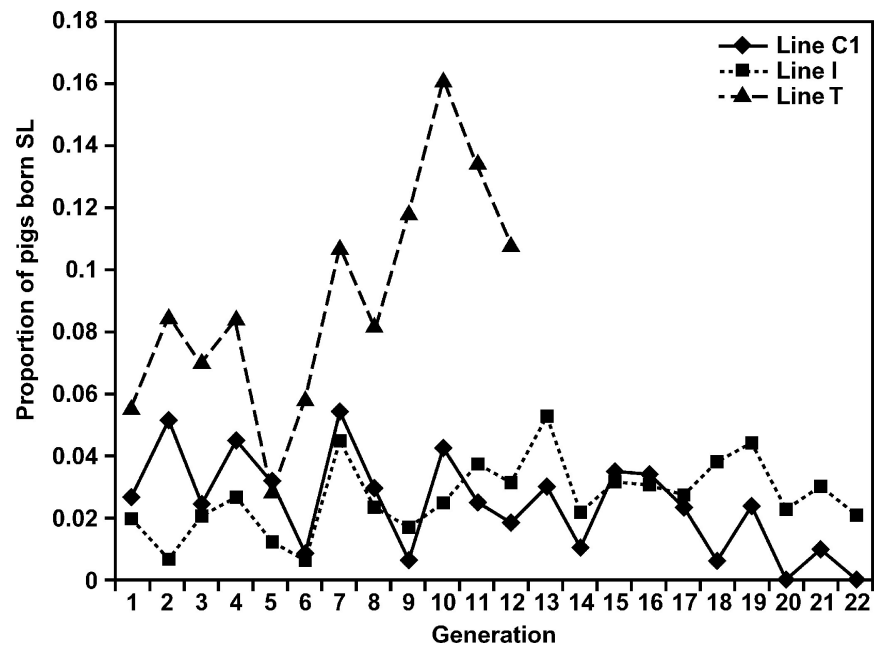

Figure 1. Proportion of pigs born splayleg (SL) by generation in Lines C1, I, and T.
Table 3. Phenotypic mean, minimum, maximum, and variance of traits tested for associations with splayleg pigs

\begin{tabular}{lrccr}
\hline \hline Trait $^{\mathrm{a}}$ & Mean & Minimum & Maximum & $\sigma^{2 \mathrm{~b}}$ \\
\hline TB & 11.49 & 1 & 34 & 10.25 \\
FF & 11.17 & 1 & 34 & 10.24 \\
MUM & 0.32 & 0 & 6 & 0.80 \\
STB & 1.08 & 0 & 14 & 2.53 \\
BA & 10.09 & 0 & 30 & 9.25 \\
OR & 16.45 & 4 & 79 & 18.67 \\
ES & 0.72 & 0.015 & 1.00 & 0.03 \\
AF, d & 370.28 & 308 & 596 & 331.76 \\
AP, d & 176.05 & 126 & 286 & 524.29 \\
NN & 14.57 & 9 & 22 & 1.69 \\
BWT, kg & 1.14 & 0.16 & 2.40 & 0.07 \\
WWT, kg & 4.30 & 0.52 & 9.90 & 0.94 \\
PINB & 0.103 & 0 & 0.308 & 0.0006 \\
SINB & 0.070 & 0 & 0.248 & 0.0005 \\
DINB & 0.074 & 0 & 0.248 & 0.0005 \\
\hline
\end{tabular}

${ }^{\text {a }} \mathrm{TB}=$ total pigs born (mummified and fully formed); $\mathrm{FF}=$ number of fully formed pigs at birth; MUM = number of mummified pigs; $\mathrm{STB}=$ number of stillborn pigs; $\mathrm{BA}=$ number of pigs born alive; $\mathrm{OR}=$ ovulation rate (ova); $\mathrm{ES}=$ embryonic survival frequency at $50 \mathrm{~d} ; \mathrm{AF}=$ age at farrowing; $\mathrm{AP}=$ age at puberty; $\mathrm{NN}=$ number of nipples; $\mathrm{BWT}=$ pig birth weight; WWT = weaning weight; PINB = pig's inbreeding coefficient; SINB = sire's inbreeding coefficient; and DINB = dam's inbreeding coefficient.

${ }^{b}$ Within line and generation variance.

and a 30-g decrease increased the likelihood by $100 \times$ $\left[(1+1.5 / 100)^{3}-1\right]=4.57 \%$, and so on.

Estimates of genetic parameters are given in Table 5. Estimates of direct and maternal heritabilities of SL were 0.07 and 0.16 , respectively. No strong genetic associations existed. Direct effects of SL were positively correlated with both direct $\left(\mathrm{r}_{\mathrm{g}}=0.23\right)$ and maternal $\left(r_{g}=0.16\right)$ effects for BWT, and negatively correlated $\left(r_{\mathrm{g}}\right.$ from -0.19 to -0.36$)$ with direct effects for BA, $\mathrm{NN}$, $\mathrm{AP}$, and ES. A correlation of 0.32 between maternal effects for SL and direct effects for BA was found. Phenotypic correlations of SL with other traits were close to zero.

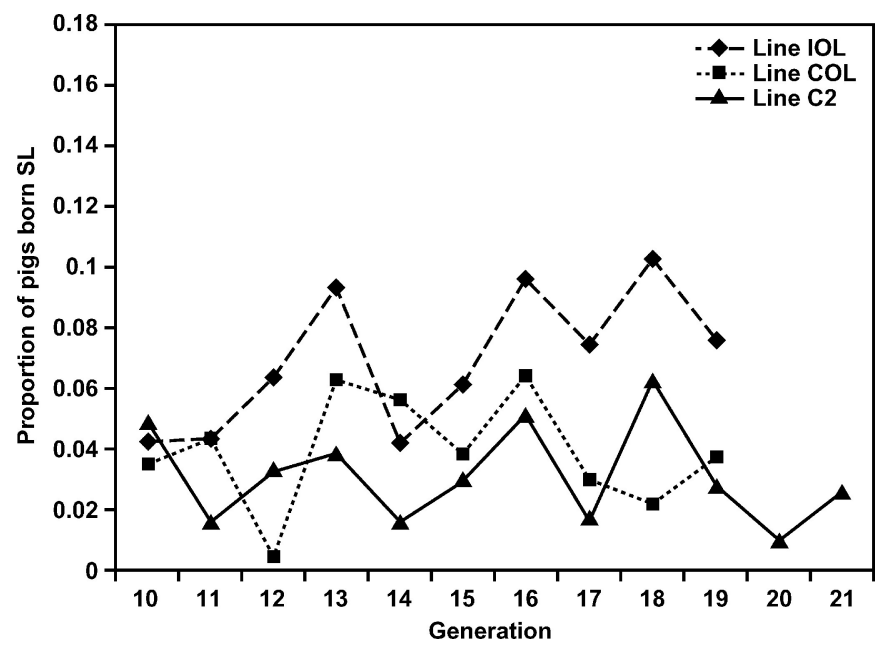

Figure 2. Proportion of pigs born splayleg (SL) by generation in Lines IOL, COL, and C2. 
Table 4. Percentage increases in likelihood of splayleg for significant effects, expressed as changes from the population mean, in logistic regression models

\begin{tabular}{llc}
\hline \hline Trait $^{\mathrm{a}}$ & Effect/change & ${\text { Increase, } \%^{\mathrm{b}}}^{\mathrm{b}}$ \\
\hline Sex & Male vs. female & $223.6^{* *}$ \\
BWT & $-10 \mathrm{~g}$ & $1.5^{* *}$ \\
DBA & $+1 \mathrm{pig}$ & $2.9^{* *}$ \\
DNN & -1 nipple & $4.6^{*}$ \\
DAP & $-1 \mathrm{~d}$ & $0.5^{* *}$ \\
DES & $-10 \%$ survival & $11.5^{*}$ \\
DINB & $+1 \%$ inbreeding & $1.5^{*}$ \\
\hline
\end{tabular}

$* P<0.05$.

$* * P<0.01$

${ }^{\text {a BWT }}$ = individual birth weight; DBA = dam's number of pigs born alive; $\mathrm{DNN}=$ dam's number of nipples; $\mathrm{DAP}=$ dam's age at puberty; DES = dam's embryonic survival at $50 \mathrm{~d}$; and DINB = dam's inbreeding coefficient.

${ }^{\mathrm{b}} \mathrm{A}$ decrease of $10 \mathrm{~g}$ from mean BWT increased the likelihood of splayleg $1.5 \%$; a 20 -g decrease increased the likelihood by $100 \times$ $\left[(1+1.5 / 100)^{2}-1\right]=3.02 \%$; a $30-\mathrm{g}$ decrease increased the likelihood by $100 \times\left[(1+1.5 / 100)^{3}-1\right]=4.57 \%$, etc.

In contrast to logistic models, analyses with linear mixed models produced incremental percentage unit changes in SL per generation in regression variables. Estimated genetic and phenotypic linear percentage unit changes in SL per generation are presented in Table 6. Trends in direct genetic effects were negative in Lines $\mathrm{C} 1$ and COL. Positive trends occurred in Lines $\mathrm{T}$, IOL, and C2. Maternal genetic trends were positive in all lines. With the exception of Line I, maternal breeding values increased faster in selected lines than in control lines.

\section{Discussion}

The incidence of abnormalities at birth is low in most populations, but it accounts for a significant proportion of preweaning deaths. Splayleg pigs have been the most common defect in newborn pigs (Jirmanova, 1983; Partlow et al., 1993) and a high percentage of pigs with SL die before weaning (Vogt et al., 1984).
Lax (1971) reported female inheritance for the SL condition, suggesting that SL was sex-linked with a varying degree of penetrance. Lax (1971) also suggested that the whole litter was affected, but there was a threshold below which pigs exhibited the SL phenotype. This finding was supported by Svendsen et al. (1990). In contrast to the work of Lax (1971), Dobson (1968) studied the incidence of SL pigs in a Landrace line and suggested that it was a polygenic trait. Based on a greater incidence of SL in Landrace than in other breeds (Vogt et al., 1984; Tomko, 1993), a genetic component for SL was inferred. In addition, Sellier and Ollivier (1982) rejected the sex-linked hypothesis, gave evidence for a polygenic hypothesis, and reported a heritability of 0.47 from a half-sib analysis. They also found evidence for maternal effects and cited increased litter size and shorter gestation length were associated with an increased rate of SL piglets.

Results reported herein indicate that sex and birth weight affect the incidence of SL pigs. Incidence of SL in males was $223.6 \%$ greater than in females. Vogt et al. (1984) found a $174 \%$ greater incidence of SL in males than females, and Svendsen et al. (1991) found males to be $233 \%$ more likely to have SL. In addition, we found that the likelihood of the SL phenotype increased 1.5\% for each decrease of $10 \mathrm{~g}$ in birth weight, a finding also supported by the results of Vogt et al. (1984) and Tomko (1993).

Five traits of the dam significantly affected the likelihood of SL pigs. The percentage of SL pigs increased as litter size increased, a result similar to those of Sellier and Ollivier (1982) and Svendsen et al. (1991). In addition, gilts that reached puberty at younger ages and had fewer numbers of nipples also were found to farrow litters of pigs with a greater incidence of SL pigs; however, age at farrowing did not significantly affect the incidence of SL pigs. Although there was variation in AP, the breeding period was approximately the same time each year for each contemporary group. Gilts were mated to farrow at an average age of $1 \mathrm{yr}$, and in those generations in which age at puberty was

Table 5. Estimates of heritabilities $\left(\mathrm{h}^{2}\right)$, phenotypic variances $\left(\sigma^{2}\right)$, genetic correlations $\left(\mathrm{r}_{\mathrm{g}}\right)$ with direct and maternal effects, and phenotypic correlations $\left(\mathrm{r}_{\mathrm{p}}\right)$ from three-trait analyses

\begin{tabular}{|c|c|c|c|c|c|c|}
\hline \multirow[b]{2}{*}{ Trait $^{\mathrm{a}}$} & \multirow[b]{2}{*}{ Effect } & \multirow[b]{2}{*}{$\mathrm{h}^{2}$} & \multirow[b]{2}{*}{$\sigma^{2}$} & \multicolumn{2}{|c|}{ SL $r_{g}{ }^{d}$} & \multirow[b]{2}{*}{$\mathrm{SL} \mathrm{r}_{\mathrm{p}}^{\mathrm{d}}$} \\
\hline & & & & Direct & Maternal & \\
\hline \multirow[t]{2}{*}{ SL } & $\mathrm{D}^{\mathrm{b}}$ & 0.07 & 0.042 & - & -0.24 & - \\
\hline & $\mathrm{M}^{\mathrm{c}}$ & 0.16 & - & -0.24 & - & - \\
\hline \multirow[t]{2}{*}{ BWT, kg } & D & 0.07 & 0.086 & 0.23 & 0.00 & -0.12 \\
\hline & M & 0.45 & - & 0.16 & -0.11 & - \\
\hline BA & $\mathrm{D}$ & 0.24 & 10.34 & -0.19 & 0.32 & -0.03 \\
\hline $\mathrm{NN}$ & $\mathrm{D}$ & 0.47 & 1.94 & -0.36 & 0.03 & 0.05 \\
\hline $\mathrm{AP}, \mathrm{d}$ & $\mathrm{D}$ & 0.49 & 754.39 & -0.19 & 0.07 & -0.03 \\
\hline $\mathrm{ES}$ & $\mathrm{D}$ & 0.14 & 0.035 & -0.32 & 0.02 & 0.02 \\
\hline
\end{tabular}

${ }^{\mathrm{a}} \mathrm{SL}=$ splayleg; BWT $=$ individual birth weight; $\mathrm{BA}=$ number of pigs born alive; $\mathrm{NN}=$ number of nipples; $\mathrm{AP}=$ age at puberty; and $\mathrm{ES}=$ embryonic survival at $50 \mathrm{~d}$.

${ }^{\mathrm{b}}$ Additive direct genetic effect.

${ }^{\mathrm{c} A d d i t i v e ~ m a t e r n a l ~ g e n e t i c ~ e f f e c t . ~}$

${ }^{\mathrm{d}}$ Correlations are between splayleg and other traits. 
Table 6. Regression coefficients (b) and SE of line genetic and phenotypic values of incidence of splayleg pigs in percentage units on generation number ${ }^{\mathrm{a}}$

\begin{tabular}{lccr}
\hline \hline Line & $\begin{array}{c}\text { Direct genetic } \\
\mathrm{b} \pm \mathrm{SE}\end{array}$ & $\begin{array}{c}\text { Maternal genetic } \\
\mathrm{b} \pm \mathrm{SE}\end{array}$ & $\begin{array}{c}\text { Phenotypic } \\
\mathrm{b} \pm \mathrm{SE}\end{array}$ \\
\hline $\mathrm{C} 1$ & $-0.274 \pm 0.004$ & $0.188 \pm 0.005$ & $-0.158 \pm 0.029$ \\
$\mathrm{I}$ & $-0.003 \pm 0.003$ & $0.106 \pm 0.004$ & $0.067 \pm 0.027$ \\
$\mathrm{~T}$ & $0.243 \pm 0.014$ & $0.527 \pm 0.024$ & $0.777 \pm 0.144$ \\
$\mathrm{IOL}$ & $0.121 \pm 0.012$ & $0.508 \pm 0.019$ & $0.472 \pm 0.123$ \\
$\mathrm{COL}$ & $-0.273 \pm 0.009$ & $0.383 \pm 0.015$ & $-0.001 \pm 0.097$ \\
$\mathrm{C} 2$ & $0.086 \pm 0.008$ & $0.113 \pm 0.012$ & $-0.042 \pm 0.079$ \\
\hline
\end{tabular}

${ }^{\mathrm{a}}$ Change in incidence of splayleg per year (i.e., the phenotypic regression for $\mathrm{C} 1$ of -0.158 is a decrease in incidence of splayleg of $0.158 \% / \mathrm{yr})$.

recorded, only $3.5 \%$ of the gilts were mated at their pubertal estrus or their first postpubertal estrus (Johnson et al., 1999). Consequently, AP and age at farrowing had a correlation of 0.17 and would not be considered similar traits. Decreased ES to $50 \mathrm{~d}$ also significantly increased the probability of SL pigs in the litter. Inbreeding of the pig did not significantly affect the incidence of SL, but the likelihood of the SL condition increased with dam's inbreeding.

The logistic models identified several maternal traits significantly associated with SL, indicating that genetic models for SL should include both direct and maternal genetic effects. Nonetheless, the magnitude of phenotypic and genetic correlations of these traits with SL in multitrait analyses was low. Because SL phenotype and birth weight were recorded on the same pig, correlations between direct and maternal genetic effects for SL and birth weight are directly interpreted. However, interpretation of the other correlations is less direct because of the way maternal traits were modeled. Phenotypic correlations are between a gilt's SL incidence and its other traits, which were all close to zero. The direct genetic correlations between SL and the other traits represent correlations between the individual's genetic merit for its own fetal development and its genetic merit for AP, NN, ES, or BA. The correlations between maternal genetic effects for SL and direct genetic effects for the other traits are between the direct genetic effects of the dam for AP, NN, ES, or BA with its genetic merit to farrow a litter with SL pigs.

Correlated responses in incidence of SL were predicted from estimates of the responses in litter size in each line and the correlation between direct genetic effects for BA and maternal genetic effects for SL pigs. Predicted maternal genetic responses per generation in percentage units were $0.159,0.323,-0.068,0.420$, 0.446, and 0.146 for Lines C1, I, T, IOL, COL, and $\mathrm{C} 2$, respectively. Predictions were relatively close to observed responses except in Lines I and T. However, in Generation 12 in Line I, index selection was discontinued, and selection on the number of $\mathrm{FF}$ pigs was practiced. From Generation 12 to Generation 22, the estimated trend in maternal genetic merit was $0.339 \pm$
0.014 percentage units, which is similar to the predicted trend. Although index selection was practiced, maternal genetic trend in SL was suppressed; however, after index selection, estimated maternal genetic trend was faster than predicted. Litter size selection, without previous selection, increased the maternal genetic trend at a rate slower than predicted. The differences between predicted and estimated responses could also be chance associations due to genetic drift. The large variation in direct genetic trend among lines indicated either no correlated response to litter size selection or genetic drift cancelled the effect of selection.

Clinical SL was described by Thurley et al. (1967) as a function of myofibrillar hypoplasia. Jirmanova (1983) expanded on this idea by suggesting that stress and hormonal imbalance of pregnant sows may adversely affect fetus development. Using Cushing's syndrome in humans as a model, in which glucocorticoids are in excess, induced glucocorticoid myopathy in rats resulted in myofibrillar hypoplasia, degeneration, and a SL phenotype. Ducatelle et al. (1986) supported this hypothesis by inducing myofibrillar hypoplasia with dexamethasone treatment in sows during late pregnancy. Svendsen et al. (1991) was able to compare SL blood serum concentrations of specific compounds to levels in normal pigs. Cortisol was abnormally high and suggested a premature release of corticosteroids. Glucose concentrations were elevated, whereas hemoglobin and insulin were lowered. They suggested that anemia would follow and lead to asphyxiation; however, Svendsen et al. (1990) found that SL pigs that survive to $\mathrm{d} 14$ have normal growth. Additionally, they found that increased blood glucose and lower hemoglobin levels in SL pigs weighing less than $1 \mathrm{~kg}$ allowed for a greater transmission of macromolecules from sow colostrum. Antalikova et al. (1996) added to this effort and reported that ultrathin sections of muscles from SL pigs had fewer myofibrils and greater accumulation of glycogen within the extramyofibrillar spaces than muscles of normal pigs.

Glucocorticoids, such as cortisol, have many effects in the body, including skeletal muscle catabolism, glucose elevation, stress response, and are needed for mammary development during pregnancy. Even though the fetal adrenal does not produce significant amounts of cortisol until late in pregnancy, cortisol is a steroid that can be easily transferred to the developing fetus from the sow. Hadley (2000) described a syndrome where excess cortisol was caused by an inhibition of the negative feedback due to a glucocorticoid receptor with decreased affinity for cortisol. One physical effect was early puberty. If selection in these lines has continuously decreased the affinity of glucocorticoid receptors to cortisol, this might explain the significant effects of age at puberty of the dam, nipple number of the dam, and birth weight associated with SL in pigs. Further research would be needed to test this hypothesis. 


\section{Implications}

Splayleg is a trait that is heritable, exhibits genetic variation, and is correlated with litter size; however, selection to increase litter size may not affect the genetic potential of individual pigs to be born with splayleg. Rather, genetic potential of sows to create a uterine environment causing splayleg may be increased due to selection for increased litter size. Because of this, splayleg should be either modeled with maternal effects or considered a trait of the sow in applied breeding programs.

\section{Literature Cited}

Antalikova, L., V. Horak, and S. Matolin. 1996. Ultrastructural demonstration of glucose-6-phosphatase activity and glycogen in skeletal muscles of newborn piglets with the splayleg syndrome. Reprod. Nutr. Dev. 36:205-212.

Boldman, K. G., L. A. Kriese, L. D. Van Vleck, C. P. Van Tassell, and S. D. Kachman. 1995. A manual for the use of MTDFREML. ARS, USDA, U.S. Meat Animal Research Center, Clay Center, NE.

Collett, D. 2002. Modelling binary data. Page 54 in Models for Binary and Binomial Data. 2nd ed. CRC Press LLC, Boca Raton, FL.

Dobson, K. J. 1968. Congenital splayleg of piglets. Aust. Vet. J. $44: 26-28$.

Ducatelle, R., D. Maenhout, W. Coussement, and J. K. Hoorens. 1986. Spontaneous and experimental myofibrillar hypoplasia and its relation to splayleg in newborn pigs. J. Comp. Pathol. 96:433445.

Hadley, M. E. 2000. Endocrinology. 5th ed. Prentice-Hall, Inc. Upper Saddle River, NJ.

Jirmanova, I. 1983. The splayleg disease: A form of congenital glucocorticoid myopathy? Vet. Res. Commun. 6:91-101.

Johnson, R. K., G. R. Eckardt, T. A. Rathje, and D. K. Drudik. 1994. Ten generations of selection for predicted weight of testes in swine: Direct response and correlated response in body weight, backfat, age at puberty, and ovulation rate. J. Anim. Sci. 72:1978-1988.

Johnson, R. K., M. K. Nielsen, and D. S. Casey. 1999. Responses in ovulation rate, embryonal survival, and litter traits in swine to 14 generations of selection to increase litter size. J. Anim. Sci. 77:541-557.

Lax, T. 1971. Hereditary splayleg in pigs. J. Hered. 62:250-252.

Partlow, G. D., K. R. Fisher, P. D. Page, K. MacMillan, and A. F. Walker. 1993. Prevalence and types of birth defects in Ontario swine determined by mail survey. Can. J. Vet. Res. 57:67-73.

Ruiz-Flores, A., and R. K. Johnson. 2001. Direct and correlated responses to two-stage selection for ovulation rate and number of fully formed pigs at birth in swine. J. Anim. Sci. 79:2286-2297.

Sellier, P., and L. Ollivier. 1982. A genetic study of splayleg in the new-born piglet. I. Multifactorial model with one threshold. Ann. Genet. Sel. Anim. 14:77-92.

Sorensen, D. A., and K. Johansson. 1992. Estimation of direct and correlated responses to selection using univariate animal models. J. Anim. Sci. 70:2038-2044.

Svendsen, L. S., B. R. Westrom, J. Svendsen, A. C. Olsson, and B. W. Karlsson. 1991. Blood serum characteristics of newborn pigs: Comparison of unaffected pigs with pigs belonging to five mortality groups. Acta. Vet. Scand. 32:287-299.

Svendsen, L. S., B. R. Westrom, J. Svendsen, A. C. Olsson, and B. W. Karlsson. 1990. Intestinal macromolecular transmission in underprivileged and unaffected newborn pigs: Implication for survival of underprivileged pigs. Res. Vet. Sci. 48:184-189.

Tess, M. W., G. L. Bennett, and G. E. Dickerson. 1983. Simulation of genetic changes in life cycle efficiency of pork production. II. Effects of components on efficiency. J. Anim. Sci. 56:354-368.

Thurley, D. C., F. R. Gilbert, and J. T. Done. 1967. Congenital splayleg of piglets: Myofibrillar hypoplasia. Vet. Rec. 80:302-304.

Tomko, M. 1993. Influence of parental origin, litter size and sex on the frequency of splayleg in piglets: A case report. Acta. Vet. Hung. 41:329-339.

Vogt, D. W., T. A. Gipson, B. Akremi, S. Dover, and M. R. Ellersieck. 1984. Associations of sire, breed, birth weight, and sex in pigs with congenital splayleg. Am. J. Vet. Res. 45:2408-2409. 